\title{
Yujiale fishing tourism and island development in Changshan Archipelago, Changdao, China
}

\author{
Ming Ming Su \\ School of Environment and Natural Resources / China Anti-Poverty Research Institute, Renmin \\ University of China \\ smm52@hotmail.com
}

\section{Geoffrey Wall}

Department of Geography \& Environmental Management, Faculty of Environment, University of Waterloo

gwall@uwaterloo.ca

and

\author{
Sangui Wang \\ China Anti-Poverty Research Institute / School of Agricultural Economics and Rural \\ Development, Renmin University of China \\ wangsg@ruc.edu.cn
}

\begin{abstract}
Tourism has long been one of the driving forces of island development, but may impose serious impacts on their physical and social composition and on island communities. Yujiale has been developed recently on many islands of China. It is a form of tourism through which households earn money by sharing fishing culture and products in the distinctive natural and cultural context of islands. This research assesses the provision of Yujiale services and products by fishing families of Digou village, Changdao Island, Changshan Archipelago, Shandong Province, China. It also assesses the community's perceptions and attitudes toward Yujiale tourism. On-site interviews and off-site analysis of online data reveal positive attitudes toward Yujiale tourism and the reinforcement of island identity among Yujiale operators. Despite offering similar services and products without much collaboration, diversification of Yujiale operations is emerging based on the varied assets of the fishing families and their engagement in fishing. However, at present, those with limited resources and capabilities are unable to take advantage of potential economic benefits. Suggestions are made to facilitate the provision of equitable opportunities to participate in and gain benefits from Yujiale tourism, so as to enhance island sustainability.
\end{abstract}

Keywords: China, development, fishing, islands, participation, tourism, Yujiale

$\underline{\text { https://doi.org/10.24043/isj.38 }}$

(C) 2017 — Institute of Island Studies, University of Prince Edward Island, Canada.

\section{Introduction}

Islands and coastal regions have been popular tourism destinations for centuries (González-Morales et al., 2016). Although not an economic activity unique to islands, tourism has been proposed by many governments and analysts as a potential livelihood strategy for islands and coastal regions, in particular, with the ability to improve living standards, reduce pressure on fishing (Fabinyi, 2010), and reinforce the islandness and island identity of island communities (Petridis et al., 2017). However, tourism may impose more impacts on islands than on many other types of destinations, 
leading to environmental and sociocultural degradation (Conlin \& Baum, 1995; Cheng et al., 2013). For many impoverished island communities, tourism may be an economic development opportunity, but it may also bring new pressures upon limited local resources (Ghosh, 2012) and pose threats to traditional livelihoods and local cultures (Nilsson, 2008).

Yujiale is a distinctive Chinese form of tourism that takes place on islands and in coastal regions (Chen \& Ren, 2007; Su et al., 2016; Tao, 2008; Xiong et al., 2011). It encourages fisher families to benefit economically by hosting or serving visitors using their existing fishing resources and local knowledge, thereby sharing lifestyles and fishing cultures with tourists. Yujiale was initiated in the coastal areas of Shandong Province in the late 1990s and has since become widespread across the coast of Eastern China (Wang et al., 2016). Different from other types of coastal or island tourism, Yujiale incorporates enjoyment of the sea with experiences of fishing culture and tradition, emphasizing personalized services and intimate host-guest relations in a family-based environment. The development of Yujiale is driven by the booming of rural tourism and the shrinking of the fishing industry in China (Su et al., 2016; Wang et al., 2016). It is a relatively new phenomenon, and existing research on Yujiale in China is centred on islands and coastal areas in Shangdong Province. There is still no national-level study on the demand for and supply of Yujiale tourism.

This paper uses analysis of online data to identify and compare the provision of Yujiale services and products by fishing families in Digou fishing village, Changshan Archipelago, Changdao County, Shangdong Province, China. On-site interviews are furthermore used to address the community's perceptions and attitudes toward Yujiale tourism. Practical implications are derived to enhance community benefits and to ensure the sustainable development of Changdao through Yujiale tourism.

\section{Literature review}

\section{Community participation and perceptions of tourism}

Destination communities are among the most important and affected stakeholders in tourism (Aas et al., 2005; Nuryanti, 1996; Scheyvens, 2003). Possessing rich local knowledge and the ability to deal with local issues (Bramwell \& Lane, 1999; Yuksel et al., 1999), they often play multiple roles in tourism (Scheyvens, 2003); receive economic, environmental, and sociocultural impacts from tourism (Wall \& Mathieson, 2006); and respond in a variety of ways to tourism development (Uriely et al., 2003). They may perceive tourism as an opportunity to enhance their living standards and to affirm their cultural identity (Perdue et al., 1990; Su \& Wall, 2012), or they may embrace negative views of tourism due to the economic, sociocultural, and environmental costs that may occur (Perdue et al., 1990; Su \& Wall, 2012). Indeed, these positive and negative perceptions and results can occur within a single community simultaneously.

Given the significance of their role in tourism, destination communities' perspectives on tourism have been extensively researched. There is a large literature on the attitudes and perceptions of residents toward tourism development in a diversity of destinations (Akis et al., 1996; Alexander, 2000; Andriotis \& Gursoy et al., 2002; Hao et al., 2011; Huh \& Vogt, 2008; Nicholas et al., 2009; Um \& Crompton 1987; Uriely et al., 2003). Behavioural responses to tourism development have been explored (Ap \& Crompton, 1993), informed by such concepts as community attachment (Nicholas et al., 2009; Um \& Crompton, 1987). Perspectives on tourism have been found to be associated with a wide variety of factors, such as the socioeconomic characteristics of destination communities, type and state of tourism development, level of tourism involvement, distance from the tourism site, dependence on tourism, and environmental attitudes (Gursoy et al., 2002; Hao et al., 2011; Jurowski \& Gursoy, 2004; Nicholas et al., 2009; Smith \& Krannich, 1998; Uriely et al., 2003; Williams \& Lawson, 2001). Perceptions and attitudes toward tourism have been found to be related to the success of tourism initiatives (Easterling, 2005) and whether or not visitors return to destinations (Hoffman \& Low, 1981). However, the findings are contingent, varying greatly from place to place, so that it is easy to overgeneralize from a single case study. This is also reason for 
encouraging the involvement of individuals in the decisions that affect their lives, for it should not be assumed that the findings from one case are readily transferable to another.

It is also important to recognize that communities are not homogenous, and perceptions and attitudes toward tourism can be diverse among residents of the same place (Andriotis \& Vaughn, 2003; Mason \& Cheyne, 2000; Nicholas et al., 2009). Furthermore, residents' attitudes and behaviours toward tourists affect tourists' experiences and thus their willingness to return (Bachleitner \& Zins, 1999; Nicholas et al., 2009), with implications for the sustainability of the sector.Destination communities seldom have genuine control over the nature and direction of local tourism because, in planning and management practices, many important decisions are often made by outsiders (Scheyvens, 2003). In recognition of this situation, many scholars have called for community participation in tourism planning and management, both in the making of decisions and the sharing of benefits (Aas et al., 2005; Nuryanti, 1996; Su \& Wall, 2012; Timothy \& Boyd, 2003; Timothy \& Tosun, 2003;), in the hope that this might minimize the potential negative impacts of tourism while achieving more satisfactory tourism development, including a higher tolerance for tourists (Timothy \& Boyd, 2003; Timothy \& Tosun, 2003).Thus, this research is informed by a large global literature on tourism and community involvement, as well as the authors' varied experiences with a diversity of community tourism situations in China. However, it is distinctive in its focus on Yujiale in a small island situation. Access to marine resources is of fundamental importance to both fishing and coastal tourism. Fishing, as a traditional livelihood of island communities, is constantly required to negotiate with island tourism development, commonly underpins the unique nature-society relationship on islands, and has important implications for island communities (Fabinyi, 2010; Pugh, 2013; Tsai \& Clark, 2003).

\section{Island tourism and Yujiale operation in China}

The necessity of a water crossing affects the accessibility of islands, often imposing an increased sense of distance and economic, political, and cultural marginalization (Baldacchino, 2004; Baum, 1997; Grydehøj, 2017; Lockhart, 1997), which may be exacerbated by limited resources, infrastructure, and provision of services (Lovelock et al., 2010; Porter, 2015). Moreover, islands, in part because of their insularity, often house fragile environments and rare wildlife, as well as unique cultural features (Baum, 1997; González-Morales et al., 2016). The biophysical attributes and institutional specificities of insularity are often associated with distinctive natural and cultural features, creating an 'island allure' that may be appealing to those from the mainland (Baldacchino, 2004; Cave \& Brown, 2012; Grydehøj, 2017; Petridis et al., 2017). Islandness, as an expression of the complex identity or sense of place of islands (Stratford, 2008), encompasses a state of tension between "openness and closure" (Baldacchino, 2004, p. 274), and may open up novel political, socioeconomic, and ecological possibilities, which may have development potential (Petridis et al., 2017). Islands have thus become popular tourism destinations worldwide, providing diverse travel experiences for tourists of different types, and tourism has long been one of the driving forces of island development which, in turn, has the potential to reinforce islandness (Cave \& Brown, 2012; González-Morales et al., 2016; Hall, 2010; Petridis et al., 2017). Although tourism may be an economic development opportunity with the potential to diversify livelihoods, reduce poverty, and empower island communities, enhanced access and the incoming of outsiders reduces insularity, changing island environments and sometimes disrupting local culture and lifestyles (Cave \& Brown, 2012; Cheng et al., 2013; Conlin \& Baum, 1995; Dhakal et al., 2011; Fabinyi, 2010; Ghosh, 2012; Jacobson \& Lopez, 1994; Klein et al., 1995; Pugh, 2013; Su et al., 2016). Therefore, the engagement of island communities, particularly vulnerable groups that may have little prior experience with tourism, should be facilitated to ensure their access to benefits while managing potential costs. It is also pertinent to assess successes and failures, particularly in the early stages of development, so that adjustments can be made. The empirical work reported below is undertaken with this in mind.

Yujiale is a distinctive Chinese version of tourism that takes place on islands and in coastal regions. It can be viewed as a particular form of Nongjiale (happy farmer) tourism that has been 
promoted as a means of rural development (Wu, 2014). Different from the resort developments that line the shores of the Mediterranean and the Caribbean, and also occur in Sanya in Hainan and some other locations in China, Yujiale requires the involvement of fishing families, and encourages host-guest interactions through the provision of participatory experiences to tourists, thereby promoting the lifestyles and cultures of fishing communities (Chen \& Ren, 2007; Su et al., 2016; Tao, 2008; Xiong et al., 2011). Yujiale tourism commonly involves staying in fishing villages, eating home-made seafood meals, participating in fishing activities, and attending the cultural events of fishing communities (Chen \& Ren, 2007). Responding to tourists' expectations of acquiring a brief exposure to the life of a fishing family, Yujiale tourism encourages the local fishing families to participate in and benefit from hosting or serving visitors using their existing fishing resources and local knowledge.

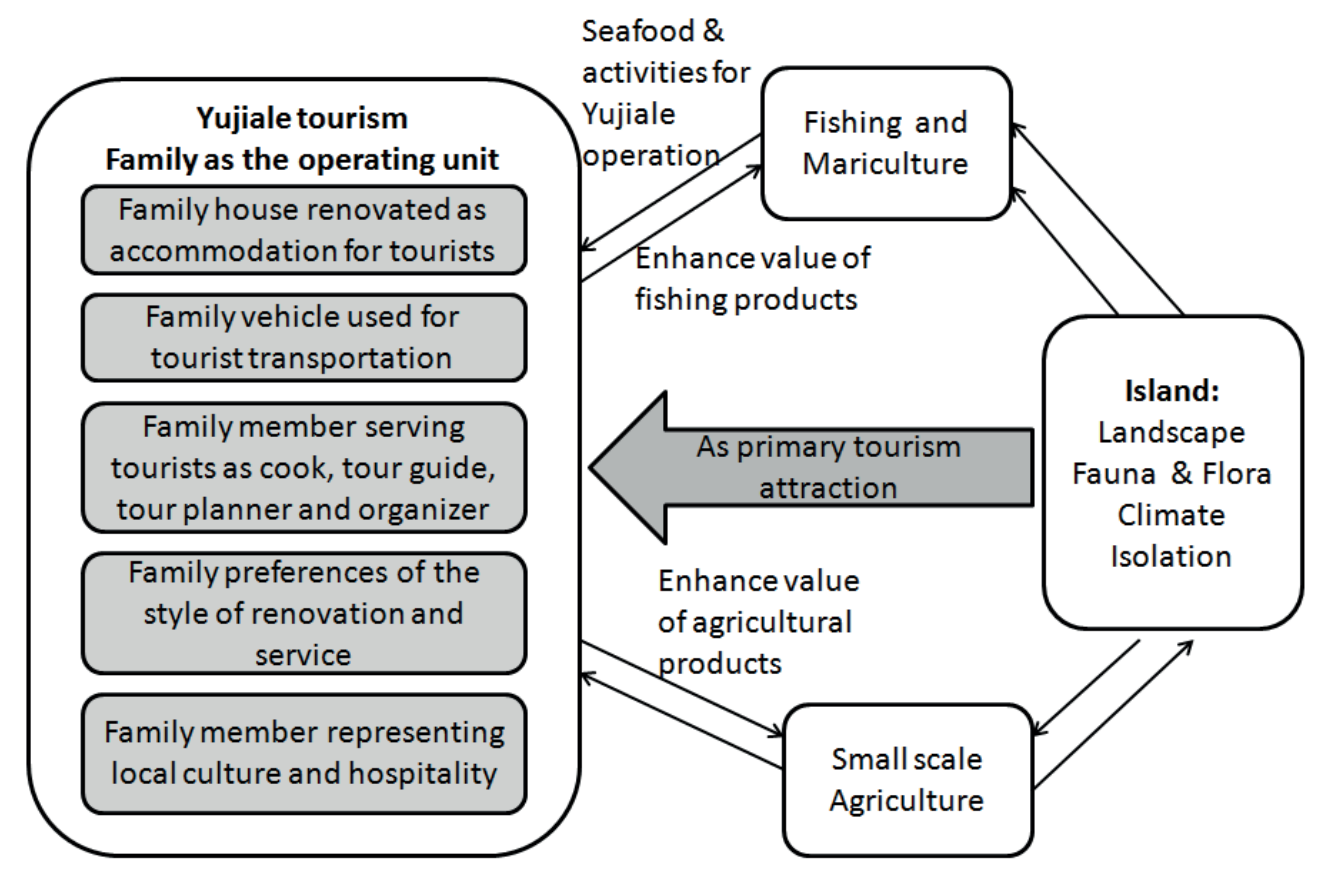

Figure 1: A synergetic relationship between fishing and tourism through Yujiale tourism. (Source: developed by the authors)

As illustrated in Figure 1, Yujiale tourism has the potential to construct a synergetic relationship between fishing and tourism on islands, both of which are seasonal and subject to changes (Su et al., 2016). Despite the heterogeneity among fishing families, Yujiale tourism has become a livelihood diversification strategy for many fishing communities in China (Chen \& Ren, 2007; Xiong et al., 2011). Such tourism can reduce the pressures on declining fish stocks by directing complementary economic benefits to fishing families (Carter \& Garaway, 2014; Su et al., 2016). Moreover, diversification of livelihoods through Yujiale tourism can reduce the risks and uncertainty of fishing (Allison \& Ellis, 2001), generate new employment opportunities, and provide extra income for fishing communities (Chen \& Ren, 2007; Xiong et al., 2011). As it depends upon their houses, boats, facilities, skills, and knowledge already gained through fishing, Yujiale tourism's initial start-up costs may be lower than for most other types of tourism (Tao, 2008). Therefore, with the rapid rise of domestic tourism in China, Yujiale tourism has been widely promoted as a development strategy for islands and coastal areas. Previous research has shown, however, that the current provision of tourism services and products by family-based Yujiale operators is generally similar, with limited collaboration, competition between families, and unbalanced distribution of benefits that largely exclude the most vulnerable, giving rise to social conflicts within the community (Su et al., 2016). These manifestations of Yujiale 
tourism must be addressed if management is to be improved and positive outcomes are to be achieved, and they are the primary focus of the empirical research that is documented in this paper.

Accordingly, a case study of Digou fishing village, Changshan Archipelago, Changdao County, Shangdong Province, China was undertaken to identify and compare the provision of Yujiale services and products by local fishing families and to understand their perceptions and attitudes toward Yujiale tourism, with a view to enhancing community benefits, making them more equitable, and fostering sustainable development.

\section{Study area: Changdao and Digou village}

Located between the Yellow Sea and the Bohai Sea on the east coast of China, Changdao is under the administration of Yantai City of Shandong Province and close to Beijing, the capital city of China. As shown in Figure 2, Changdao consists of the Changshan Archipelago, which is comprised of 32 islands, with a total land area of $56 \mathrm{~km}^{2}$, a coastline of $146 \mathrm{~km}$, a sea area of $8,700 \mathrm{~km}^{2}$, and a 2014 population of around 16,800 distributed across 40 villages (CDGW, 2016). North and South Changshan Islands are the two largest and most-populated islands of Changdao. The latter is conveniently connected with Yantai City, with ferry services taking roughly 40 minutes. This serves as the major transportation connection of Changdao to the mainland for both island residents and tourists. The road system has been developed on these two islands, connecting major tourism sites and villages.

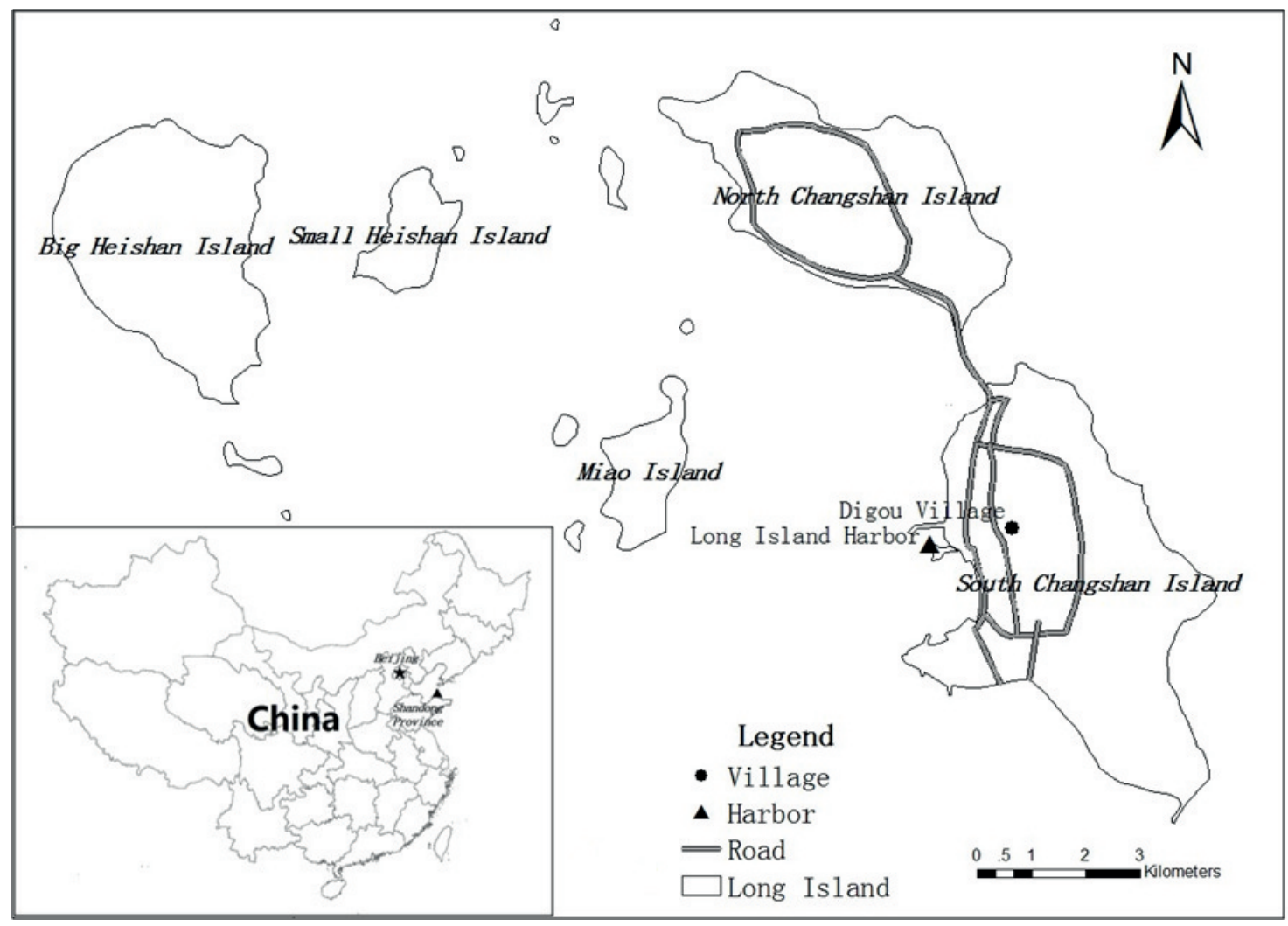

Figure 2: The location of Digou village, Changdao County, Shandong Province, China. (Source: Map made by the authors using ArcGIS software)

With a mild climate, island scenery, and rich natural resources, including a national geo-park, Changdao is rated as a national 4A level tourism site (the highest ranking) and is one of China's top ten tourism islands. Yantai City is itself a popular coastal resort with a promenade and numerous seafront hotels. Urban visitors from Beijing and Tianjin are major sources of tourists to Changdao, 
comprising about 35\% of the total number of tourists in 2012 (CDGW, 2016). These tourists visit Changdao primarily for beach activities and to enjoy the coastal scenery and local seafood.

Tourism activities in Changdao are currently concentrated on the South and North Changshan Islands. The former is the largest and most-visited island, with a land area of $12.8 \mathrm{~km}^{2}$ and a coastline of $20 \mathrm{~km}$. Here, eight villages are engaged in Yujiale tourism. Digou village was selected as the study site because it was one of the earliest fishing villages to become involved in tourism. It is located on the west coast of the island, just steps away from the harbour where the ferry offloads tourists from the mainland city of Yantai (Figure 2). Digou has a population of 660 in about 200 families.

\section{Methodology}

Qualitative approaches were used to gain an understanding of Yujiale tourism in Digou, and a triangulation strategy was employed to compare and synthesize findings from different sources. Participatory observation was important for gaining an initial understanding and for confirming insights gained in other ways. However, the majority of information used in this study comes from two sources: digital data obtained off-site and interview data gathered on-site. Each will be considered in turn.

Use of digital data in tourism community research

The development of the Internet and information technology has permeated many aspects of tourism, including how people search for information and make decisions during the pre-trip stage, how people experience the site, and how they reflect during the post-trip stage (Wu \& Pearce, 2013; Wu et al., 2014). The Internet has evolved from being a broadcasting medium to a participatory platform that allows people to interact and share information, and it has become a rich database for tourism researchers (Wu et al., 2014). Although excluding cohorts that never or seldom access the Internet, the online information that tourists generate is widely considered as providing unbiased insights and real voices from insiders' perspectives (Kozinets, 2010; Yoo \& Gretzel, 2008). It can also have substantial influence on potential tourists (Mauri \& Minazzi, 2013; Rong et al., 2012).

A wide variety of research has drawn upon online sources, but most such research has used tourist-generated data to explore their travel experiences and perceptions (Wu \& Pearce, 2013; Wu et al., 2014). In comparison, little has been done using online platforms to explore the provision of tourism services and products by destination communities. However, the form and content of information posted on web-based tourism platforms also reflects suppliers' perceptions and attitudes toward tourism, and can be a useful source of information on communities involved in tourism.

Table 1: Yujiale operators at Digou village identified from Changdao tourism websites. Data retrieved on 22 December 2016.

\begin{tabular}{|l|l|l|}
\hline Changdao Tourism Website & $\begin{array}{l}\text { No. of Yujiale } \\
\text { operators }\end{array}$ & $\begin{array}{l}\text { No. of } \\
\text { comments }\end{array}$ \\
\hline $\begin{array}{l}\text { Blue Penglai Tourism Website } \\
\text { http://www.penglaiu.com/yujiale/changdao/ }\end{array}$ & 5 & 350 \\
\hline $\begin{array}{l}\text { Blue Changdao Website } \\
\text { http://www.cdyou.net/ }\end{array}$ & 6 & 153 \\
\hline $\begin{array}{l}\text { Changdao Yujiale Tourism Website } \\
\text { http://www.sdcd.net/ }\end{array}$ & 3 & 42 \\
\hline $\begin{array}{l}\text { Touring Changdao Website } \\
\text { http://www.cdyok.com/ }\end{array}$ & 1 & 13 \\
\hline
\end{tabular}


On-site interviews identified four Changdao tourism websites on which local Yujiale operators post their information to interact with and attract tourists (Table 1). These websites were reviewed thoroughly, and all posts submitted from 2014 to 2016 at Digou village were identified. In total, 15 posts from 13 operators were retrieved, which were numbered from Yujiale No. 1 to No. 13 for easy reference in the analysis. Photographs and other content submitted by Yujiale operators were collected. Each post contained 300 to 1,000 Chinese characters and 10 to 20 images. Major themes were identified in both texts and photographs, categorized, recorded in an Excel document, and compared. Visitor comments are not included in the analysis as the focus of this research is on the perspectives of operators and other residents.

\section{On-site data collection}

Two one-week field investigations were conducted in August 2014 and February 2015 by two undergraduate students at Renmin University, one of whom is a resident of Changdao. Semi-structured interviews were first conducted with the village mayor and the village committee to gain their perspectives on the status of tourism development and community participation, issues and concerns at the village level, and aspirations for the future. Then, village residents were interviewed, including both participants and non-participants in tourism. The former refers to those who had been involved in tourism for more than one year, and the latter refers to those not involved directly in any tourism-related activities. Tourism participant resident interviews were undertaken to understand their socioeconomic characteristics, type of tourism participation and its contribution to family livelihoods, attitudes toward tourism participation, issues and concerns, and aspirations for the future. Interviews with those not involved in tourism revealed their socioeconomic characteristics, reasons for not participating in tourism, attitudes toward tourism, issues and concerns, and aspirations for the future. A snowball technique was used to acquire interview respondents. Tourism participant respondents were first recommended by the village mayor and then each respondent in subsequent interviews. A convenience sampling method was used to engage non-tourism participants, concentrating on those who live close to interviewed tourism participants. Potential participants were approached, and the research purpose was explained. Approval was obtained orally before an interview was conducted. The response rate for both types of participants was about 50\%. Twelve village resident interviews were conducted, including eight participants and four non-participants. Each interview lasted from one to two hours. Three-quarters of the respondents were female. The major age category was between 25 to 50 years, and $75 \%$ of respondents had high school or university educations.

In addition, participant observation was conducted while the researchers stayed at a Yujiale operation. Field notes were taken on types of tourism participation, tourism infrastructure in the village, performance of tourism-related businesses, and the daily lives of village residents.

In summary, data were collected from on-site interviews and participant observation as well as off-site online sources to gain a comprehensive understanding of the provision of Yujiale tourism products and services and perceptions and attitudes toward this type of island tourism.

\section{Findings}

Drawing from a variety of data sources, the status of tourism development in Changdao and Digou village is first assessed. Next, provision of Yujiale tourism services and products is analyzed. Then, residents' perceptions of and attitudes toward Yujiale tourism are presented.

\section{Tourism development in Changdao and Digou village}

Fishing and mariculture used to be the two main economic activities in Changdao. With a decline in fishing resources and the resulting contraction in household income, tourism has been promoted by the local government since 1997. Tourism development has been encouraged through the conversion of fishery lands (coastal fish hatcheries) to tourism uses, development of tourism 
resources and facilities, the marketing of Changdao to targeted sources of visitors, the registration of Yujiale participants, and the provision of $¥ 11,000$ (roughly US $\$ 1,600$ ) in government subsidies to Yujiale participants since 2013.

These measures have been effective. More than 800 families in 16 villages are involved in Yujiale operations, offering more than 10,000 beds in Changdao (CDGW, 2016; Xiong et al., 2011). According to a Changdao Government Report (CDGW, 2016), about 85\% of the archipelago's tourists stayed overnight in 2010, and their average spending on the island reached $¥ 560$ (around US\$93) per person. In Changdao, both annual tourist numbers and revenues have increased dramatically, but the annual tourism revenue has experienced a higher rate of increase, indicating that the ability to generate income from tourists has been enhanced (Figure 3).

Tourism in Changdao is highly seasonal: Tourist numbers peak during the May holidays, summer vacations in July and August, and the National Day holiday in October. There are scarcely

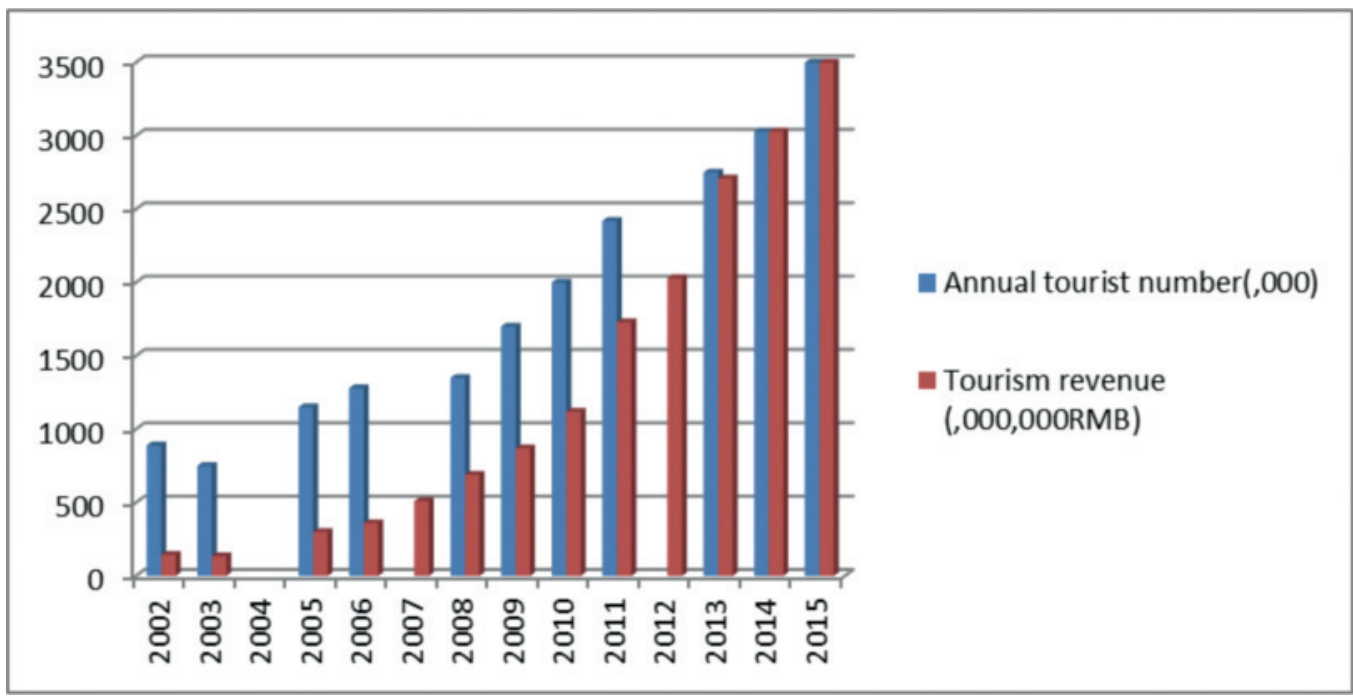

any visitors during the winter months. Interviewees indicated that the fishing season runs primarily from April to May and from September to October, with little overlap with the tourism season, facilitating the co-existence of the two livelihood activities.

Figure 3: Changdao tourism statistics (2002-2015). Note: Annual tourist numbers and revenues decreased in 2003, mainly due to SARS in China. Statistics for 2004, 2007, and 2012 are not available. (Source: Changdao Government Reports 2003-2016, Changdao Government Website: http://www.changdao.gov.cn/cn/content/gov/gzbg/index.jsp)

With its locational advantage adjacent to the ferry terminal, Digou village has engaged in Yujiale tourism since 2004. Some families initiated tourism businesses offering seafood meals and in-house accommodation before 2000, an activity that later came to be called Yujiale. According to the village mayor, about 40 families were registered for Yujiale operations in 2014, with a capacity of roughly 600 beds and annual reception of 16,000 tourists. In addition to the Yujiale operators, many residents are involved in tourism or the provision of related services, such as part-time labour for Yujiale operators, souvenir vending, and providing equipment for water-based recreation activities. The village mayor indicated that tourism generates about $40 \%$ of the annual income of the village.

\section{Provision of Yujiale tourism products and services}

Being family-based, most Yujiale operators start their business through renovating and enlarging their houses. As illustrated in online posts, Yujiale tourism provision is generally similar in terms of facilities, activities, and meals. However, being operated by family members, each Yujiale is characterized by the personal preferences and personalities of its owners, such as its renovation style and ways of communication with tourists. Besides providing home-style accommodations and meals, many 
Yujiale operators also provide transportation services to and from the port and within the island, acting as tour guides and trip organizers. Their interactions with tourists showcase the local culture and hospitality. Figure 4 provides examples of Yujiale provision at Digou village.

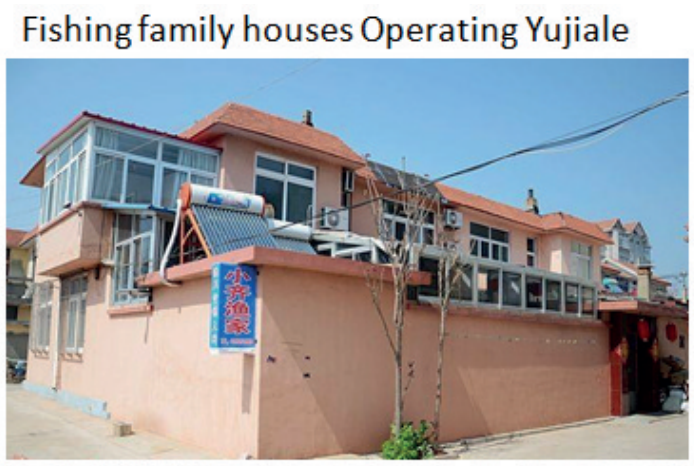

Catering services of Yujiale
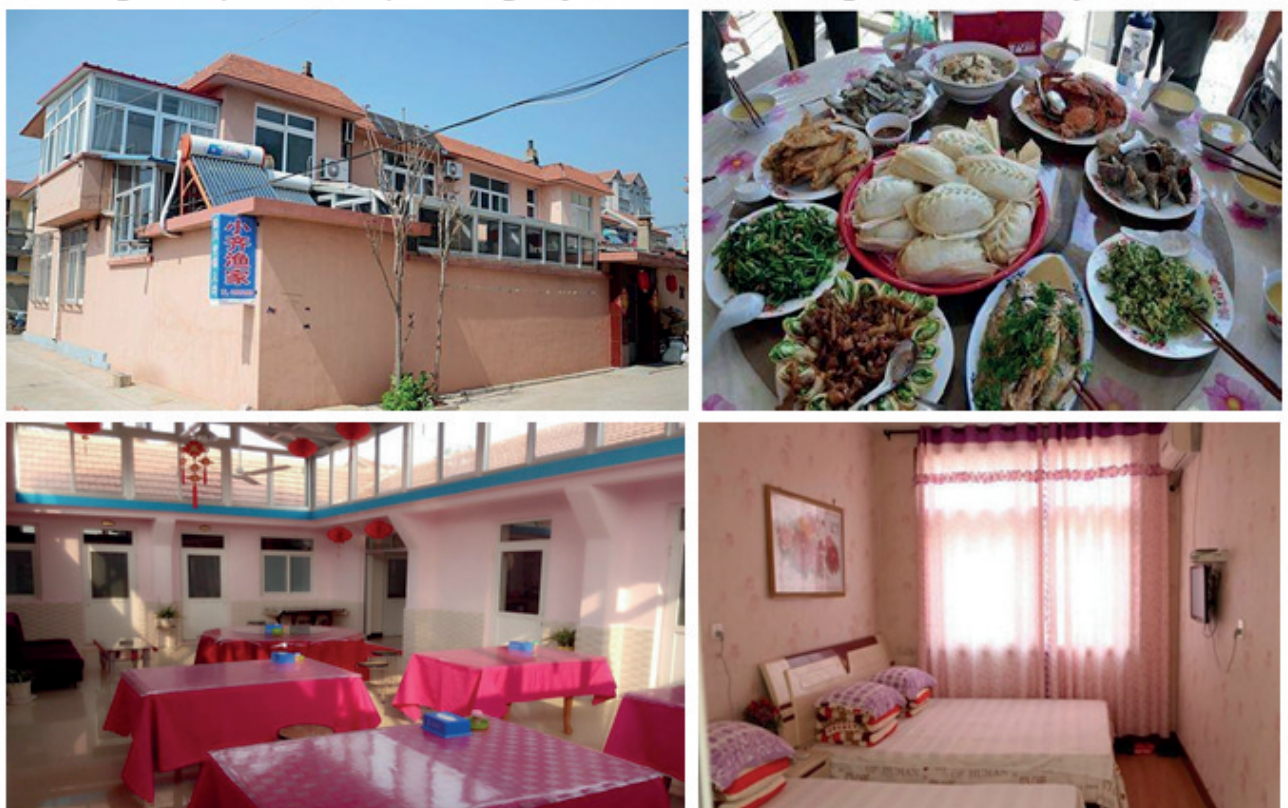

Yujiale restaurant

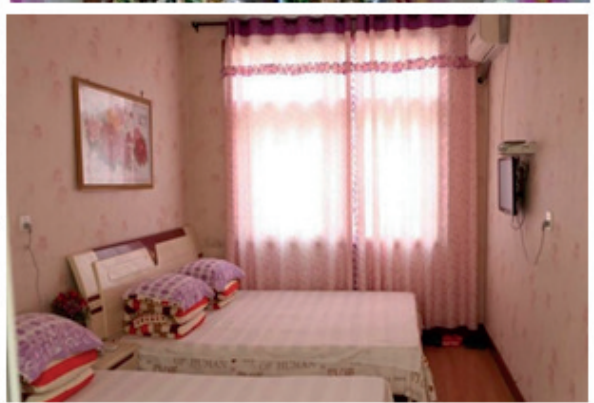

Home style accommodation

Figure 4: Examples of Yujiale provision in Digou village, Changdao. (Source: Research team)

Table 2: Yujiale services and products derived from 13 online posts.

\begin{tabular}{|c|c|c|c|}
\hline Category & Key features & Presentation & $\begin{array}{l}\begin{array}{l}\% \text { of } \\
\text { coverage } \\
\star\end{array} \\
\end{array}$ \\
\hline Location & $\begin{array}{l}\text { Close to port } \\
\text { Close to scenic spots }\end{array}$ & Text & $92 \%$ \\
\hline Transportation & $\begin{array}{l}\text { Free transportation to and from port } \\
\text { Transportation service within the island } \\
\text { Own vehicle }\end{array}$ & Text & $100 \%$ \\
\hline Facilities & \begin{tabular}{|l|} 
Accommodation \\
Entertainment
\end{tabular} & Text + image & $100 \%$ \\
\hline $\begin{array}{l}\text { Food and } \\
\text { cooking }\end{array}$ & \begin{tabular}{|l|} 
Fresh seafood \\
Local cooking method and traditional dishes
\end{tabular} & $\begin{array}{l}\text { Text +image } \\
\text { Text +image }\end{array}$ & $\begin{array}{l}100 \% \\
100 \% \\
\end{array}$ \\
\hline Activities & \begin{tabular}{|l|l|} 
Fishing \\
Sightseeing
\end{tabular} & Text + image & $85 \%$ \\
\hline $\begin{array}{l}\text { Service } \\
\text { standard }\end{array}$ & $\begin{array}{l}\text { Local hospitality } \\
\text { Honest and reliable }\end{array}$ & Text + image & $77 \%$ \\
\hline Price & \begin{tabular}{|l} 
Price \\
Value for money \\
\end{tabular} & Text & $100 \%$ \\
\hline Certificate & $\begin{array}{l}\text { Government certificate } \\
\text { Long-term business }\end{array}$ & Text + image & $38 \%$ \\
\hline $\begin{array}{l}\text { Contact } \\
\text { information }\end{array}$ & Multiple ways of communication & Text & $100 \%$ \\
\hline
\end{tabular}

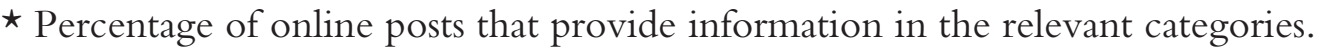


The price of Yujiale ranges from $¥ 150-¥ 300$ (US\$25-50) per person per night, as posted online and indicated in interviews, depending on location, standard of service, and season, and usually includes accommodation and three meals. The price is lower than that of regular hotels and includes the benefit of eating fresh, home-cooked seafood and experiencing the lifestyle of a fishing family and enjoying their hospitality.

Services provision and products of Yujiale tourism have been categorized based on online posts and verified through interviews and observation (Table 2). Five key features were identified as being emphasized in online posts: local seafood meals, participatory fishing activities, hassle-free experiences and personalized services, fishing culture and local hospitality, and business and service reliability.

Meals comprised of local seafood, featuring fresh products from the sea and local cooking methods, are one of the key attractions of Yujiale. Therefore, it is emphasized by all online posts, usually with 5-10 images of seafood dishes. Local seafood cuisine is often complemented by use of local produce, highlighting the links between local fishing and small-scale agriculture. One post states:

We offer all kinds of fresh-caught seafood cooked in the local style, including a variety of molluscs, fish, and shrimp, featuring fish dumplings, seafood buns, homemade shrimp sauce, and much more. Our own garden supplies fresh vegetables you can pick yourself. (Yujiale No. 1)

With close ties to fishing and the fishing culture, many Yujiale operators customize participatory fishing activities for tourists with the convenience of their own fishing and mariculture operations. This is illustrated by the following comments:

We have our own fishing boat and sea cucumber breeding area, supplying all fresh seafood for our guests. You will not forget the taste of fresh seafood harvested in the morning! Interested visitors can also go fishing with us in the morning or visit our sea cucumber farm to experience our fishing operations. (Yujiale No. 2)

In addition, the fishermen also provide free fishing gear and barbecue appliances, so that visitors can experience the fun of fishing and barbecue. (Yujiale No. 7)

Hassle-free free travel experiences with personalized services and products are emphasized in most online posts, which distinguishes Yujiale from other types of accommodation such as hotels or hostels. Based on their personal experiences of the local culture and environment, Yujiale owners can provide insiders' suggestions on tour arrangements and provide personalized travel services based on tourists' needs at a low cost:

We can help you to plan your trip according to your time and personal preferences. We can also help you arrange outdoor activities such as catching seafood, fishing, watching the sunrise, and so on. Staying with us, you will enjoy our one-stop-shop services! (Yujiale No. 6)

Besides standard Yujiale services and products, many online posts comment on local hospitality as part of the local culture to show that they welcome tourists. The following excerpts from online posts demonstrate how Yujiale operators perceive their hospitality and its relevance to Yujiale operation:

Being natives of the island, we welcome friends from all over the world to be our guests; we will make your stay happy and satisfying. (Yujiale No. 9) 
We were born on the island and are familiar with island customs, stay with us, we will show you island hospitality. (Yujiale No. 12)

Yujiale business and service reliability is another feature that is demonstrated by long-term operation and Yujiale certification from the government, as shown in the following quote from one online post:

Opened in 1993, we are committed to welcoming our guests with a reasonable price, warm service, delicious food, and a comfortable environment. With a good reputation built up through 20 years of business, we have many repeat customers. In 2013, we were awarded 'Four Star Yujiale' by Shandong Tourism Bureau. (Yujiale No. 1)

These features are used to distinguish Yujiale from ordinary accommodations: residents are involved in providing personalized service and products; exposure to local culture; and links are formed among tourism, fishing, and agriculture. Many of these features, including fishing culture, seafood, and local hospitality, are closely related with island identity and are clearly communicated with pride and emphasized in online posts to tourists. It indicates that Yujiale operators positively reinforce their island identity through the process of Yujiale operation.

Perceptions of and attitudes to Yujiale tourism

Participation in tourism has been recognized as an important means of livelihood diversification for many families. All tourism interviewees acknowledged that their household income increased after operating Yujiale. The village mayor commented that the annual contribution from tourism ranges from $¥ 30,000$ to $¥ 100,000$ (US $\$ 5,000$-US $\$ 16,000$ ) at the household level, based on the length of involvement and scale of operation. However, with around 40 households engaged in Yujiale, benefits are not spread widely across the village, particularly for those with limited resources and capacities. According to both residents and the mayor, no actions are currently being undertaken by the village committee to support Yujiale and encourage wider participation.

A high level of satisfaction with their current tourism business was identified among tourism participants: $12.5 \%$ were very satisfied, and $62.5 \%$ were satisfied. Moreover, all respondents indicated that they were not concerned about the change of lifestyle due to tourism and expressed willingness to continue or even expand their tourism business in the future. However, two out of four non-tourism informants indicated that their lives were negatively affected by Yujiale tourism, such as by noise and crowding in the summer. These interruptions are not considered to be serious, and no opposition to tourism was identified, indicating that negative impacts are not substantial at the current stage of development. Two non-participants indicated their willingness to engage in Yujiale in the future if the situation permits, and three indicated that they desire financial support from the local government to start a Yujiale operation.

\section{Discussion}

Yujiale tourism, engaging the unique natural and sociocultural features of islands, is designed to forge links among tourism, fishing, and mariculture to diversify community livelihoods and promote regional economic development. Both personal interviews and a review of online posts show that Yujiale operators at Digou village reinforced their island identity, associated with the livelihood and lifestyle of fishing in an island context, by demonstrating fishing practices and communicating island narratives to tourists.

The research shows that positive economic benefits are highly acknowledged by Yujiale operators, and resident perceptions of Yujiale tourism are generally positive. Five key features were identified: seafood meals, participatory fishing activities, hassle-free experience and personalized services, exposure to fishing culture and local hospitality, and business and service reliability. However, there is not much product diversification in Digou village. Small differences 
occur through the style of renovation of homes and the style of communication with tourists based on suppliers' preferences and personalities.

Yujiale tourism is centred on the provision of food and accommodation, with few other value-added participatory experiences to enable in-depth immersion into the fishing community. Therefore, more cultural components could be added to showcase the lifestyles of island fishing communities and provide more opportunities for the active involvement of tourists. For example, activities such as traditional seafood preparation, cooking classes, and shell art workshops could be organized. Tourists' experiences could thereby be enriched, there would be new opportunities for village residents to get involved, and Digou's competitive advantages would be strengthened.

Resource availability strongly influences residents to position either Yujiale or fishing as their primary livelihood strategy. Those not participating in tourism were either heavily engaged in fishing or lacked sufficient resources to develop Yujiale tourism. Large-scale Yujiale tourism operators indicated plans to enlarge their tourism business, with little interest in expanding their fishing activities. Those with limited resources or capacities are unable to participate and thus cannot access most of the economic benefits of Yujiale development. In the long run, this situation could lead to social conflict, and measures should be undertaken by the local government to enhance the involvement of disadvantaged and vulnerable groups to address the increasing income gap.

Current Yujiale operations are primarily family-based, engaging resources and capacities primarily of family members without much collaboration within the village. The village government has yet to take actions to support Yujiale tourism, particularly in terms of supportive policies and infrastructure. This situation has hindered the establishment of minimum operating standards for Yujiale services and the overall competitiveness of Digou village. To address this, the village committee, rooted in the community, with a deep understanding of its resources and development prospects, should play an active leadership role in supporting and facilitating Yujiale tourism development. In particular, village-scale infrastructure enhancement is needed to improve road conditions and signage. A village plan should be made to better allocate and utilize resources for Yujiale tourism.

A Yujiale association should be set up at the village level, involving current Yujiale operators as well as families and individuals with the potential to develop their own Yujiale or to supply labour to Yujiale businesses. Such an association could establish minimum standards, conduct joint promotions, negotiate with tour operators, create village-level tourism activities, arrange skills training, share experiences among operators, and refer tourists. This would encourage cooperation and reduce competition among Yujiale operators, establish business linkages with tourism operators and suppliers, and enrich experiences for tourists. In particular, it would help to promote collaborations between tourism and non-tourism participants in the village through diversifying methods of involvement and generating casual employment opportunities-such as transportation provision, tour guiding, or help in kitchen-for individuals with insufficient resources to operate a Yujiale of their own. Then, the tourism benefits could be better retained and more widely distributed in the village to ensure that vulnerable groups can be reached.

\section{Conclusions}

Community-based Yujiale tourism, incorporating fishing culture and island lifestyles with tourism experiences, has been developed on many islands in China and has achieved positive outcomes in boosting regional economic development, enhancing island livelihood sustainability, and promoting and reinforcing island identity. Yujiale tourism has thus been widely acknowledged as a suitable development opportunity for island communities.

Taking Digou village in Changdao in Shandong province as a case, this study has used off-site online posts and on-site interviews to understand and evaluate the supply of Yujiale tourism. It has been shown that positive outcomes have been achieved and are widely acknowledged among fishing communities, but more could be done to diversify the product and reduce competition through enhanced organization at the village level. 
Although useful insights have been gained and suggestions for improvement have been made, the sample of informants is small, particularly of residents not involved in Yujiale tourism. Assessment of website information on Yujiale operators and their businesses has the restriction of excluding those who do not engage in online promotions either due to personal choices, lack of skills or resources, or because of the small scale of their Yujiale operations. Therefore, a more extensive community survey is needed to further explore community perceptions and attitudes, and it should ideally include Yujiale operators at different scales of development and be conducted in multiple locations to ascertain similarities and differences between destinations with different geographical and social contexts. Furthermore, demand-side investigations with tourists should be undertaken to understand their expectations and experiences, complementing the supply-side studies, leading to a more complete understanding of Yujiale tourism to inform its further development and chart a sustainable future.

\section{Acknowledgements}

Special thanks to Wang Jie and Su Mengyang, who conducted the field research, and all the interviewees for their kind help and support. The research received financial support from the Major Project of the National Social Science Foundation of China: 'Research on the mechanism and policy on implementing targeted poverty reduction' (15ZDC026) to Dr. Sangui Wang.

\section{References}

Aas, C., Ladkin, A., \& Fletcher, J. (2005). Stakeholder collaboration and heritage management. Annals of Tourism Research, 32(1), 28-48. https://doi.org/10.1016/j.annals.2004.04.005

Akis, S., Peristianis, N., \& Warner, J. (1996). Residents' attitudes to tourism development: the case of Cyprus. Tourism Management, 17, 481-494. https://doi.org/10.1016/S0261_ $\underline{5177(96) 00066-0}$

Alexander, S.E. (2000). Resident attitudes towards conservation and black howler monkeys in Belize: the Community Baboon Sanctuary. Environmental Conservation, 27(4), 341-350. https://doi.org/10.1017/S0376892900000394

Andriotis, K., \& Vaughn, R. (2003). Urban residents' attitudes toward tourism development: the case of Crete. Journal of Travel Research, 42(2), 172-185.

https://doi.org/10.1177/0047287503257488

Allison, E., \& Ellis. F. (2001). The livelihoods approach and management of small-scale fisheries. Marine Policy, 25(5), 377-388. https://doi.org/10.1016/S0308-597X(01)00023-9

Ap, J., \& Crompton, J. (1993). Residents' strategies for responding to tourism impacts. Journal of Travel Research, 32(1), 47-50. https://doi.org/10.1177/004728759303200108

Bachleitner, R., \& Zins, A.H. (1999). Cultural tourism in rural communities: measuring resident views via survey research. Journal of Business Research (3), 199-209. https://doi.org/10.1016/S0148-2963(97)00201-4

Baldacchino, G. (2004). The coming of age of island studies. Tijdschrift Voor Economische En Sociale Geografie, 95(3), 272-283. https://doi.org/10.1111/j.1467-9663.2004.00307.x

Baum, T. (1997). The fascination of islands: a tourist perspective. In D.G. Lockhart \& D. Drakakis-Smith (Eds.), Island tourism: trends and prospects (pp. 21-35). London: Pinter.

Bramwell, B., \& Lane, B. (1999). Collaboration and partnerships for sustainable tourism. Journal of Sustainable Tourism, 7(3-4), 179-181. https://doi.org/10.1080/09669589908667335

Carter, C., \& Garaway, C. (2014), Shifting tides, complex lives: the dynamics of fishing and tourism livelihoods on the Kenyan coast. Society \& Natural Resources, 27(6), 573-587. https://doi.org/10.1080/08941920.2013.842277

Cave, J., \& Brown, K.G. (2012). Island tourism: destinations: an editorial introduction to the special issue. International Journal of Culture, Tourism and Hospitality Research. 6(2), 95-113. https://doi.org/10.1108/17506181211233036 
CDGW (2015). Changdao Government Website. http://www.changdao.gov.cn/cn/content/gov/gzbg/index.jsp

Cheng, T.M., Wu, H.C., \& Huang, L.O. (2013). The influence of place attachment on the relationship between destination attractiveness and environmentally responsible behavior for island tourism in Penghu, Taiwan. Journal of Sustainable Tourism, 21(8),1166-1187. https://doi.org/10.1080/09669582.2012.750329

Chen, M.B., \& Ren, G.Y. (2007). Study on the recreational fishery development and countermeasure of Changdao County. Fisheries Economy Research, 3, 37-40. (in Chinese)

Conlin, M.V., \& Baum, T. (1995). Island tourism: management principles and practice. New York: Wiley \& Sons.

Dhakal, N.P., Nelson, K.C., \& Smith, J.L.D. (2011). Resident well-being in conservation resettlement: the case of Padampur in the Royal Chitwan National Park, Nepal. Society \& Natural Resources, 24(6), 597-615. https://doi.org/10.1080/08941921003709633

Easterling, D. (2005). Residents and tourism. Journal of Travel \& Tourism Marketing, 18(4), 4964. https://doi.org/10.1300/J073v18n04_04

Fabinyi, M. (2010). The intensification of fishing and the rise of tourism: competing coastal livelihoods in the Calamianes Islands, Philippines. Human Ecology, 38, 415-427. https://doi.org/10.1007/s10745-010-9329-z

Grydehøj, A. (2017). A future of island studies. Island Studies Journal, 12(1), 3-16. https://doi.org/10.24043/isj.1

Ghosh, T. (2012). Sustainable coastal tourism: problems and management options. Journal of Geography and Geology, 4(1), 163-169. https://doi.org/10.5539/jgg.v4n1p163

González-Morales, O., Álvarez-González, J.A., Sanfiel-Fumero, M.A., \& Armas-Cruz, Y. (2016). Governance, corporate social responsibility and cooperation in sustainable tourist destinations: the case of the island of Fuerteventura. Island Studies Journal, 11(2), 561-584.

Gursoy, D., Jurowski, C., \& Uysal, M. (2002). 2002 Resident attitudes: a structural modeling approach. Annals of Tourism Research, 29, 79-105. https://doi.org/10.1016/S01607383(01)00028-7

Hall, M. (2010), Island destinations: a natural laboratory for tourism. Asian Pacific Journal of Tourism Research, 15(3), 245-249. https://doi.org/10.1080/10941665.2010.503613

Hao, H., Long, P., \& Kleckley, J. (2011). Factors predicting homeowners' attitudes toward tourism: a case of a coastal resort community. Journal of Travel Research, 50(6), 627-640. https://doi.org/10.1177/0047287510385463

Hoffman, D.L., \& Low, S.A. (1981). An application of the probit transformation to tourism survey data. Journal of Travel Research, 20(2), 35-38. https://doi.org/10.1177/004728758102000206

Huh, C., \& Vogt, C.A. (2008). Changes in residents' attitudes toward tourism over time: a cohort analytical approach. Journal of Travel Research, 46, 446-455. https://doi.org/10.1177/0047287507308327

Jacobson, S.K., \& Lopez, A.F. (1994). Biological impacts of ecotourism: tourists and nesting turtles in Tortuguero National Park, Costa Rica. Wildlife Society Bulletin, 22(3), 414-419.

Jurowski, C., \& Gursoy, D. (2004). Distance effects on residents' attitudes toward tourism. Annals of Tourism Research, 31, 296-312. https://doi.org/10.1016/j.annals.2003.12.005

Klein, M.L., Humphrey, S.R., \& Percival, H.F. (1995). Effects of ecotourism on distribution of waterbirds in a wildlife refuge. Conservation Biology, 9(6), 1454-1465. https://doi.org/10.1046/j.1523-1739.1995.09061454.x

Kozinets, R.V. (2010). Netnography: doing ethnographic research online. Thousand Oaks, CA: Sage. Lockhart, D. (1997). Islands and tourism: an overview. In D. Lockhart \& D. Drakakis-Smith (Eds.), Island tourism: trends and prospects (pp. 3-20). London: Pinter. 
Lovelock B., Lovelock, K., Normann, Ø. (2010). The big catch: negotiating the transition from commercial fisher to tourism entrepreneur in island environments, Asia Pacific Journal of Tourism Research, 15(3), 267-283. https://doi.org/10.1080/10941665.2010.503616

Mason, P., \& Cheyne, J. (2000). Residents' attitude to proposed tourism development. Annals of Tourism Research, 27(2), 391-411. https://doi.org/10.1016/S0160-7383(99)00084-5

Mauri, A.G., \& Minazzi, R. (2013). Web reviews influence on expectations and purchasing intentions of hotel potential customers. International Journal of Hospitality Management, 34(1), 99-107. https://doi.org/10.1016/j.ijhm.2013.02.012

Nicholas, L.N., Thapa, B., \& Ko, Y.J. (2009). Residents' perspectives of a World Heritage Site: the Pitons Management Area, St. Lucia. Annals of Tourism Research, 36(3), 390-412. https://doi.org/10.1016/j.annals.2009.03.005

Nuryanti, W. (1996). Heritage and postmodern tourism. Annals of Tourism Research, 23, 249260. https://doi.org/10.1016/0160-7383(95)00062-3

Perdue, R.R., Long P.T., \& Allen, L. (1990). Resident support for tourism development. Annals of Tourism Research, 17(4), 586-599. https://doi.org/10.1016/01607383(90)90029-Q

Petridis, P., Fischer-Kowalski, M., Singh, S. J., \& Noll, D. (2017). The role of science in sustainability transitions: citizen science, transformative research, and experiences from Samothraki island, Greece. Island Studies Journal, 12(1), 115-134. https://doi.org/10.24043/isj.8

Porter, B.A., Mark, B., Orams, M.B., Lück, M. (2015). Surf-riding tourism in coastal fishing communities: a comparative case study of two projects from the Philippines. Ocean $\mathcal{E}$ Coastal Management, 116, 169-176. https://doi.org/10.1016/j.ocecoaman.2015.07.015

Pugh, J. (2013). Speaking without voice: participatory planning, acknowledgment, and latent subjectivity in Barbados. Annals of the Association of American Geographers, 103(5), 1266-1281. https://doi.org/10.1080/00045608.2012.706571

Rong, J., Vu, H.Q., Law, R., \& Li, G. (2012). A behavioral analysis of web sharers and browsers in Hong Kong using targeted association rule mining. Tourism Management, 33(4), 731-740. https://doi.org/10.1016/j.tourman.2011.08.006

Smith, M., \& Krannich, R. (1998). Tourism dependence and resident attitudes. Annals of Tourism Research, 25, 783-802. https://doi.org/10.1016/S0160-7383(98)00040-1

Stratford, E. (2008). Islandness and struggles over development: a Tasmanian case study. Political Geography, 27(2), 160-175. https://doi.org/10.1016/j.polgeo.2007.07.007

Su, M.M., \& Wall, G. (2012). Global-local relationships and governance issues at the Great Wall World Heritage Site, China. Journal of Sustainable Tourism, 20(8), 1067-1086. https://doi.org/10.1080/09669582.2012.671330

Su, M.M., Wall, G., \& Jin, M. (2016). Island livelihoods: tourism and fishing at Long Islands, Shandong Province, China. Ocean \& Coastal Management, 122, 20-29. https://doi.org/10.1016/j.ocecoaman.2015.11.014

Tao, W.L. (2008). Study on Yujiale tourism at Penglai. Journal of Shandong Youth Administrative Cadres College, 23(6), 55-56. (in Chinese)

Timothy, D.J., \& Boyd, S.W. (2003). Heritage tourism. Edinburgh Gate: Pearson Education.

Timothy, D.J., \& Tosun. C. (2003). Appropriate planning for tourism in destination communities: participation, incremental growth and collaboration. In S. Singh, D.J. Timothy \& R.K. Dowling (Eds.), Tourism in destination communities (pp. 181-204). Wallingford: CABI. https://doi.org/10.1079/9780851996110.0181

Tsai, H.M., \& Clark, E. (2010). Nature-society interactions on islands: introduction. Geografiska Annaler, 85(4), 187-189. https://doi.org/10.1111/j.0435-3684.2003.00141.x

Um, S., \& Crompton, J.L. (1987). Measuring residents' attachment levels in a host community. Journal of Travel Research, 26(1), 27-29. https://doi.org/10.1177/004728758702600105 
Uriely, U., Israeli, A., \& Reichel, A. (2003). Religious identity and residents' attitudes toward heritage tourism development: the case of Nazareth. Journal of Hospitality $\mathcal{E}$ Tourism Research, 27(1), 69-84. https://doi.org/10.1177/1096348002238881

Wall, G., \& Mathieson, A. (2006). Tourism: change, impacts and opportunities. Harlow: Pearson Education.

Williams, J., \& Lawson, R. (2001). Community issues and resident opinions of tourism. Annals of Tourism Research, 28, 269-290. https://doi.org/10.1016/S0160-7383(00)00030-X

Wang, T.F., Ma, R.F., \&Wu, D.D. (2016). Progress of research on Yujiale in China. Journal of Sichuan Institute of Tourism, 6, 58-61. (in Chinese)

Wu, M.Y., \& Pearce, P.L. (2013). Appraising netnography: towards insights about new markets in the digital tourist era. Current Issues in Tourism, 17(5), 463-474. https://doi.org/10.1080/13683500.2013.833179

Wu, M.Y., Pearce, P. L., Huang, K.J., \& Fan, T.T. (2014), 'Gap year' in China: views from the participants and implications for the future. Current Issues in Tourism, 18(2), 158-174. https://doi.org/10.1080/13683500.2014.946478

Wu, X. (2014). The farmhouse joy (nongjiale) movement in China's ethnic minority villages. The Asia Pacific Journal of Anthropology, 15(2), 158-177. https://doi.org/10.1080/14442213.2014.894556

Xiong, T., Feng, Z.B., Qi, L.H., Tu, Y.Q., Shen, Q.F., Cheng, C.M., \& Yu, C.Y. (2011). Analysis of influencing factors of Yujiale tourism in Changdao County. Hunan Agricultural Sciences, 11, 44-47. (in Chinese)

Yoo, K.H., \& Gretzel, U. (2008). What motivates consumers to write online travel reviews? $\begin{array}{lllll}\text { Information Technology } \quad \& \quad \text { Tourism, } & \text { 10(4), }\end{array}$ https://doi.org/10.3727/109830508788403114

Yuksel, F., Bramwell, B., \& Yuksel, A. (1999). Stakeholder interviews and tourism planning at Pamukkale. Turkey Tourism Management, 20, 351-360. https://doi.org/10.1016/S02615177(98)00117-4 